\title{
The Conceptualization of Immigration in Jhumpa Lahiri's The Namesake
}

Jahida Nuradin Yousif ${ }^{1 *}$ and Yasir Allawi Al-Jumaili ${ }^{2}$

${ }^{7}$ M.A Student, Soran University, Kurdistan, Iraq

${ }^{2}$ Assistant Professor., Koya University, Kurdistan, Iraq

Corresponding Author: Yasir Allawi Al-Jumaili, E-mail: Jahida.yousif@soran.edu.iq

\section{ARTICLE INFORMATION}

Received: November 01, 2020

Accepted: January 09, 2021

Volume: 4

Issue: 1

DOI: 10.32996/ijllt.2021.4.1.8

\section{KEYWORDS}

Conceptual Metaphor Theory, Jhumpa Lahiri, Source Domain, Target Domain, Cross-Domain Mapping, Immigration

\section{ABSTRACT}

This paper attempts to analyse the metaphorical representation of immigration in Jhumpa Lahiri's novel The Namesake (2003). It aims to explore the way in which the process of immigration is conceptualized in terms of experiences from other domains. Lahiri as the second generation of immigrants is brought up in the family that experienced the process of immigration. However, the notion of immigration among Lahiri's critics is explored, but a few number of researches approached its metaphorical language, whereas the current paper investigates immigration in terms of the stylistic investigation of immigration metaphors in the light of cognitive approach. This study also examines the mapping process, which is used to conceptualize immigration in the novel. It applies insights from Conceptual Metaphor Theory by George Lakoff and Mark Johnson to the linguistic expression that underlie conceptual metaphors that are selected from the novel. In addition, it identifies all the source domains that are used in the selected expressions to represent the target domain of immigration, through the mapping process. The immigration process in Lahiri's The Namesake is compared to ' sort of lifelong pregnancy', 'perpetual wait', ' constant burden', 'free', and 'packing a pillow and a blanket'. The selection of the conceptual metaphor theory provides a deeper understanding of the way the process of immigration is represented.

\section{Introduction}

Immigration is a process that challenges one's own culture, language, and the sense of belonging. People emigrate from their homeland to the host land due to various conditions. The vast process of immigration to The West started after the Second World War from the once-colonized countries (Rumbaut, 1994), and India was one of those countries. The Indian- American novelist, Jhumpa Lahiri (1967-present), is one of those writers whose work is highly appreciated due to her ability in representing immigrants' challenges in the host land; she pays a meticulous attention to both first and second generation of immigrants in the process of their assimilation to the new country. Many critics have examined the South Asian American diasporic writer, Jhumpa Lahiri's works concerning the identity's complexities, homelessness, displacement and hybridity. She has been acclaimed to be a truthful, reflecting mirror that represents the diasporic experience from a migrant perspective in her fiction. In 2014 President, Barak Obama, awarded her National Medals of Arts and Humanities at the White House, recognizing her fiction as "rare truth" he stated that her works represent the truth that they experience, "they deepen and broaden our great American story and the human story" (Obama, 2015). He claims that her stories do not only display the truth of the migrants' experience, but Americans' and human beings in general. However, it would be easy to classify her stories as another kind of immigrant fiction, merging related themes of uprootedness and hybridity. Her themes and emotions are universal which lead her fiction to a much larger dimension of human experience, because she creates kinship and beauty in places where are least expected. Those stories are not only connected to schizophrenic world of immigrants, but could be located anywhere (Chand qtd. in Dhingra, 2012, p. 12).

Since the publication of Interpreter of Maladies (1999), her literature is defined as American, Indian American, Asian American, post-colonial, South Asian, Bengali, and global (Dennihy, 2012). The scholars who investigated her works have tried to stay

K C AL-KINDI CENTER R D FOR RESEARCH AND DEVELOPMENT Your gateway to world-class research

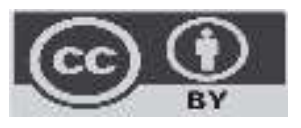

Published by Al-Kindi Center for Research and Development. Copyright (c) the author(s). This open access article is distributed under a Creative Commons Attribution (CC-BY) 4.0 license 
focused on transnationalism, identity, cultural assimilation, and estrangement. While deeming the migrants' cultural dilemmas and dislocations, Lahiri does not only limit immigrants' dilemma in foreign land but projects immigration as a permanent human condition. According to Pathak, Dabir, and Mishra (2008) Lahiri does not only portray Indian immigrants who feel that they are psychologically and physically dislocated, she also presents that the immigrants from any culture have the same feelings in a different domain culture. Lahiri's critics claim that her own experience as a child of immigrant parents is the source of inspiration; as a result, many of them analyze her works depending on her biography. The reason behind this claim is that in many interviews she declares that both first and second-generation immigrants inherit the sense of exile, whether directly or indirectly. The first generation of immigrants experience it directly, while the second generation sense it from their immigrant parents. The challenges of loneliness, exile, constant sense of alienation, and the constant longing for the lost world are more complicated for the parents. In an interview with Alden Mudge that she states " no matter how much we create our own lives and choose what we want out of life, it is very difficult to escape our origins" (Mudge, 2003). For her one's origin plays an important role in shaping the personality, her origins lead and decorates her fiction. She continues by saying," [a]lot of the novel rose out of my experience of growing up" (Mudge, 2003). Therefore, the studies that were conducted on her fiction mostly place their focus on the contexts that deal with culture, ethnic identities, culture of immigrants, post colonialism, gender, and food; Indian cuisine invades a large space in her works.

Most of her critics depend on the fact that she has a direct experience of immigration, and the way her parents taught her Indian culture and language. She felt the bond neither with her mother tongue nor with the language of the host land, which is English, but the current study avoids approaching Lahiri's works using the biographical link. The current study aims to investigate the way she represents immigration. The previous studies primarily focused on contexts, historical backgrounds, and India as a country, which experienced colonialism in Lahiri's fiction, but I will use language of the texts as the only evidences and guidance to approach the way she conceptualizes immigration in the light of cognitive linguistics.

\section{Literature Review}

Lahiri has published her first Pulitzer Prize winner, collection of stories Interpreter of Maladies (1999), which examines the subjects of marriage, alienation, dislocation, the loss of identity and culture. Later she published her first novel The Namesake (2003) that entails the outcomes and consequences of the immigration process that results in encountering conflicts in immigrant's identity. Another collection of short stories Unaccustomed Earth (2008) was published, different from the formers by embracing the process of assimilation of the immigrants and striking the roots into the unaccustomed earth. In this collection, she portrays the hardships of immigration as smoother for the first generation of immigrants. In 2013, her second novel The Lowland (2013) was published, in which it she tries to make India present for her parents who live in America. I consider the absence of any reviews on the conceptualization of immigration in Lahiri's works, thus the current research enriches the existing literature about her fiction in terms of the representation of immigration. The aim of this section is to survey the previous literature that has been done, concerning Lahiri's works.

However, the conceptual metaphor theory has not been used in the similar framework in her fiction, but Lahiri's works have gain popularity since her first publication; as a result, there are many journal articles, PhD dissertations, theses, and a limited number of books about her narratives. Ramona Alice Bran in her PhD dissertation, entitled Immigration 'A Lifelong Pregnancy'? An Analysis of Jhumpa Lahiri's Fiction (2014) provides a detailed analysis of Lahiri's fiction. She explores cultural translation, transnational belongings, interpretations, and transplanted identities. She approaches Lahiri's narratives mostly depending on the ideas of the postcolonial theorists such as Homi Bhabha and Gayatry Chakravorty Spivak; primarily on Spivak's essay can the subaltern speak? She thinks that the immigrant's emergence of third-space and in-Betweenness leads to their transnationality. The author's argument is supported and guided primarily by the ideas of critics and scholars such as Homi Bhabha, Gayatry Chakravorty, and Edward Soja.

On the other hand, Pooja Joshi's article, "How many voices here?" A Study of the fictional works of Jhumpa Lahiri explores Lahiri's short stories narratives applying Mikhail Bakhtin's remark on verbal discourse as a social phenomenon and polyphony to inspect the relation between language, culture, and the acculturation of identity in the frame of diaspora. In contrast to other studies on the Lahiri's works, Joshi studies her fictional short stories' language. She uses a stylized approach to delve and examine the language that plays a considerable role in the construction of the Diasporas. As a result, the author, Joshi explores that in her narratives, one character has different voices. She claims that Lahiri mixes the first and third person narrative to show that the self-construction process is complicated. Moreover, author believes that using first person narratives less than the third person, and this triumph of switching strategy" do not necessarily emphasize a clash between voices about the home and diaspora, but rather a clash within voices about home and diaspora" ( Joshi, 2016). 
The core of Jhumpa Lahiri's narratives is the dilemmas of immigrants, yet there are scholars who have examined them through the feminist theory lenses. Since it is not only males, who undergo the process of immigration, likewise females in her narratives are paired with males to complete the circle of immigration. For example, article A Study of Jhumpa Lahiri's Women from Feminist Perspective by Doppalapudi Subba Rao and Dr. Pravin Joshi examine the way women are portrayed from a feminist standpoint, in which the impacts of immigration are different on women and men. The authors claim that Lahiri's point of view towards feminism is different from other Indian postmodern feminist writers for she portrays immigrant women in foreign countries. They call Lahiri's women characters as "ethno-centric" (Subba \& Joshi, 2019)

In addition to the numerous scholarly articles, theses, dissertations, and reviews, there are many books written about Jhumpa Lahiri's works. They mostly explore the process of naming, diasporic experience and culture acculturation as their primary discourse. In the following account, I will briefly survey the most prominent ones in a chronological order The book Jhumpa Lahiri: The Master Storyteller (2002) by Suman Bala consist of thirty essays, primarily by Indian scholars, this book only includes essays as a critical response to Lahiri's collection of short stories The Interpreter of Maladies. Another efficient book by Nigamanada Das entitled Jhumpa Lahiri: Critical Perspective (2008) includes several articles about various themes. However, the only article that deals with metaphor The Metaphors of Pain: Reflections on Interpreter of Maladies by Buddhadeb Roy Choudhury in which he studies and explores the metaphors of pain experienced by female characters. Vandana Pathad, Urmi la Dbir, and Shubha Mishra label Lahiri as one of the female writers of contemporary fiction in a book entitled Contemporary Fiction: An Anthology of Female Writers (2008). The book contributors investigate Lahiri's works only in two articles, but it is credential to be among other diasporic female writer in this anthological edition. One of the articles is Enigma of Cultural Interface: A Study of Diasporic Experience in Jhumpa Lahiri's The Namesake by Jyoti Patil, she discusses that Lahiri presents the cultural dilemmas and the stories of assimilation. Whereas the other article is Literature Still Matters! The Namesake: Women Reads Women by Prem Srivastava. He explores the way the novel The Namesake has been adapted to a movie by Mira Nair, similar to Patil he claims that the novel is the portrayal of the trauma of culturally displaced characters. Another book, Naming Jhumpa Lahiri: Canons and Controversies (2012) by Lavina Dhingra and Floyd Cheung as editors, the books consists of nine chapters, it depicts Lahiri's fiction in the context of historical, political, and artistic context. The authors argue that Lahiri's fiction explores both universal human experience, and to be more specific Indian immigrants' diasporic life.

As we have seen from the above section, most of the previous studies about Lahiri took various routes to approach her works. None of the above mentioned studies examined her works from a cognitive perspective; therefore, my study would be different from them. I will use a cognitive tool to argue about the representation of immigration in selected expression chosen from The Namesake. At this stage, my work will be limited to few metaphorical expressions as I am conducting a pilot study to check the feasibility of this approach.

\section{Methodology}

This paper applies insights from the conceptual metaphor theory by George Lakoff and Mark Johnson (1980) in the book Metaphors WE Live By to the metaphorical expressions that are extracted from Lahiri's novel The Namesake. The conceptual metaphor theory thoery is performed in this paper to help us with a better understanding of the metaphors of immigration in Lahiri's novel. George Lakoff and Mark Johnson's prominent book Metaphors We Live By (1980) initiated the conceptual metaphor theory, thenceforth; it has become the field of interest for the contemporary scholars. According to Lakoff and Johnson that "the human conceptual system is metaphorically structured and defined" (Lakoff \& Johnson, 1980, p. 7). They claim that metaphor rests in thought, not merely in language, however, the identification of metaphors is worked out through the linguistic expressions, and they are the representation of metaphors that are processed in one's thought.

Conceptual metaphor theory was developed through the framework of cognitive linguistics, under a wider scope, which is cognitive science, because they target human cognition system at the very beginning. As Hogan (2003, p. 29) argues, "cognitive science is an interdisciplinary study aimed at understanding human cognition", since human mind has a complex system while processing the concepts, as a result it is easier for human being to utter and express through the conceptualization of things. This approach claims that language is more than merely words and works on human thought (Evans \& Green, 2006, p. 5), in other words the linguistic expressions are the reflections of the cognitive process of mind.

Moreover, Lakoff and Johnson, Kovecses, and Turner argue that metaphor is not only embedded in the language of poetics, but in ordinary language of everyday use as well. Moreover, Most of the metaphorical expressions given in Metaphors We Live By are derived from ordinary language and are highly metaphorical in nature. For instance, in the conceptual metaphor LOVE IS A JOURNEY (Lakoff \& Johnson, 2003, p. 45; Kovecses, 2010, p. 175) in this utterance, the concept of love is understood in term of a more concrete and familiar expression, which is, journey. Moreover, another set of the daily expressions that are the realizations 
of conceptual metaphor LOVE IS A JOURNEY such as Look how far we have come, we are at crossroads. We will just have to go our separate ways. We cannot turn back now; I do not think this relation is going anywhere (Lakoff \&Johnson, 2003, p. 45). Moreover, it has been a long bumpy road (Kovecses, 2010, p. 104). Since, the concept of love is difficult to understand, so when it is extended into a metaphorical expression it is projected into a clear expression through the concept of journey. Likewise, the conceptual metaphorical ARGUMENT IS WAR is another popular expression, which is constantly repeated, in our everyday language through a range of different expressions such as your claims are indefensible, he attacked every weak point in my argument, his criticisms were right on target, I demolished his argument, I have never won an argument with him, you disagree. okay, shoot!, and if you use that strategy, he will wipe you out, he shot down all of my arguments (Lakoff \&Johnson, 2003, p. 5). In accordance with the previous example, we conclude that the concept of argument is explained through the concept of war. It is presented in our practical language, through the verbs 'winning', 'attacked', 'shoot', 'wipe out', 'shot down', arguments are understood in terms of war. The people whom are we arguing with are considered as opponent, we attack their position to save our own. It is significant to mention that not every characteristic of war are structured into the domain of argument, but partially. In addition, it is not hard and challenging to construct metaphors; nevertheless, we use them automatically and subconsciously. Everyone, even children, accesses metaphors because metaphor is an integral part of our everyday thought and language. When we claim that the metaphor is a matter of thought, by thought Lakoff and Turner argue that "it is about all kinds of thought; thought about emotion, about society, about human character, about language, and about the nature of life and death" (Lakoff \& Turner, 1989, p. xi).

Furthermore, according to Lakoff and Johnson's model, each conceptual metaphors consist of two parts, 'target domain' and 'source domain'. When those conceptual metaphors are understood as matter of thought, the target domain is understood in terms of source domain through a process called cross-domain mapping. Similarly, Zoltan Kovecses in his book Metaphor, argues that there are two concepts in the process of metaphor formation and calls them as ( $A$ and $B$ ). When it is said that $A$ is understood in terms of $B$, it is not understood randomly, but there is "a set of systematic correspondences between the source and the target in the sense that constituent conceptual elements of B corresponds constituent elements of $A$ " ( Kovecses, 2012, p. 7). To him these correspondences, which are conceptual, are referred to as the mapping between both domains. Having the existing similarities between both domains is not the condition for the conceptual metaphor formation, whereas this kind of similarity is achieved and produced in the systematic correspondence of mapping. For example in the LOVE IS A JOURNEY one might think that a set of preexisting similarities between the concept of love and the journey is already there, whereas the domain of love did not possess those elements before it was projected into the journey.

The paper uses insights from Lakoff and Johnson's theory of metaphor to show the way immigration is represented in Lahiri's novel The Namesake, it also aims to identify the linguistic expression that operate as source domains in the text, followed by running the cross-domain mapping between the source and the target domain.

\section{Analysis of Immigration Metaphors in The Namesake}

Lahiri's first novel, The Namesake is adapted to a film directed by Mira Niar in 2006. It was adapted to film because it represents the real experiences of Indian immigrants in The United States of America. Lahiri's The Namesake contains a great number of linguistics manifestations of conceptual structure and mapping, but due to the paper's restriction, I will only discuss and provide the analysis of selected linguistic expressions that are seen as the realization of the conceptual metaphors, which connote the process of immigration.

In the following extract, Ashima describes her status, as an immigrant, a homesick Ashima, who is one of the main characters from The Namesake, is an Indian Immigrant in the United States of America. She is married to an Indian immigrant, Ashoke, who is a $\mathrm{PhD}$ candidate to study the electrical engineering. Ashima has left India after the marriage, while Ashoke has already been to America. The way that Ashima experiences the process of immigration differs from Ashoke's experience. For example, her status of being an immigrant is described as follows (Lahiri, 2003)

Though no longer pregnant... For being a foreigner, Ashima is beginning to realize, is a sort of lifelong pregnancy- a perpetual wait, a constant burden, a continuous feeling out of sorts. It is an ongoing responsibility, a parenthesis in what had once been ordinary life, only to discover that the previous life has vanished, replaced by something more complicated and demanding. Like pregnancy, being a foreigner, Ashima believes, is something that elicits the same curiosity from the strangers, the same combination of pity and respect. (P. 60)

The above extract is the most quoted passage from Lahiri's fiction, because it carries the theme of her fiction in a new and creative way, in which it spins around the immigration and immigrant's status. In this extract, a number of metaphorically used expressions are used to represent the way the process of immigration is experienced by the immigrants. It is a complex network 
that consists of multiple source domains working simultaneously to feed the representation of immigration. It is significant to have an idea about the context in which this extract is used to provide the liability for non-literal meaning of the metaphorically used expressions. The context of the above excerpt is when Ashima is no longer pregnant, and gave birth to her first child, Gogol. In addition, they have moved to live in a university town outside Boston, where they are the only Bengalis. Ashoke is quite comfortable and happy with his new profession, as a university professor, while for Ashima it is different. She is still in her status of being a foreigner.

Ashima uses the linguistic expression 'a sort of lifelong pregnancy' to characterize the way a non-native residents experiences the process of immigration. The noun phrase 'a sort of lifelong pregnancy' is used metaphorically, because the contextual meaning differs from the basic meaning of the noun phrase. It is used to show how Ashima for being a foreigner feels in the host land. Ashima, unlike Ashok, fails to find solace and comfort in the new society; makes her feel lonely and depressed (Macwan, 2014, p. 113). The linguistic expression' a sort of lifelong pregnancy' is the metaphorical focus in the above extract, because it used metaphorically. Additionally, it represents the concept of immigration in which it cannot be expressed through its literal use. The target domain of the immigration is not explicitly mentioned or directly used in the discourse, but it can be inferred through the context. For example, the target domain of immigration can be inferred by the use of 'for being a foreigner', it implies the concept when someone is not a native citizen in a country or a refugee, and to state the feeling of being no home. Consequently, the concept of immigration is understood in terms of 'a sort of lifelong pregnancy'. Conceptually, in the expression above, the source domain of pregnancy is mapped onto the target domain of the immigration. Lahiri uses pregnancy but in a new abnormal way, because the pregnancy that she mentions does not last in its normal period, but it lasts forever. The concept of immigration as a target domain is demonstrated through a more common and concrete process that is pregnancy, in which Lahiri meticulously explains at the starting chapters of the novel, and expressed through Ashima's character, it is a burdensome and annoying process, as "she wipes sweat from her face with the free end of her sari. Her swollen feet ache against speckled gray linoleum. Her pelvis aches from the baby's weight" (Lahiri, 2003, p. 9). The metaphor's structure is straightway placed on the similarity of the characteristics and disruption that a woman might feel during the pregnancy. Immigration as a target domain and pregnancy as a source domain are conceptually expressed through a language that could be used in everyday language, what makes the readers surprised is Lahiri's diction of pairing both pregnancy and the concept of immigration. In addition, the characteristics such as weight, burden, and longevity are mapped from the source domain of pregnancy to the target domain of immigration. The application of mapping helps readers to understand the way immigrants feel and experience immigration, in which it is experienced in terms of being a burden which is permanent and lasts forever. As previously explained the linguistic metaphor 'a sort of lifelong pregnancy' is the linguistic realization of the conceptual metaphors that can be concluded as IMMIGRATION IS AN EDNLESS JOURNEY, IMMIGRATION IS A BURDEN and IMMIGRATION IS HEAVY.

In the same context and excerpt from the novel, another metaphorically used expression is used as the source domain for the target domain of immigration. Ashima' state as being an immigrant, which a foreigner is represented in terms of "a perpetual wait" (Lahiri, 2003, p. 60). Contextually, Ashima describes her status as she was no longer pregnant and in a perpetual wait for the child but, her perpetual wait is still present. However, the literal waiting for the baby has ended, but for her as an immigrant, it has never ended. Ashima's status as an immigrant in the United States of America is the representation and the construction of the way of diasporic life, likewise her journey begins as an alien immigrant to a diasporic statelessness (Raychaudhuri, 2018 p.84). Conceptually, the noun phrase 'a perpetual wait' is metaphorically used to portray the immigration at the conceptual level, therefore it is possible to think of the expression 'perpetual wait' nonliterally, because the character, Ashima, does not mean that immigration is a literal perpetual wait. The meaning of the linguistic expression "perpetual wait" can be inferred as nonliteral. As far as the conceptual mapping is concerned, the source domain 'perpetual wait' provides the conceptual structures to the target domain. Ashima, as the speaker, maps partial structures such as happening repeatedly and annoyance from source domain to the target domain of immigration. Therefore, immigration is similar to an endless wait. The analogy between them both is that immigration is type of waiting that is constantly rotating and does not have a destination; there is nowhere to reach. Therefore, the conceptual metaphor of immigration is a perpetual wait can be concluded. As the result of the cross-domain mapping, the linguist expression 'perpetual wait' can be considered as a linguistics realization that underlies the conceptual metaphor: IMMIGRATION IS WAITING.

In the same fashion, another linguistic expression that enriches the process of immigration as a conceptual phenomenon. Here Ashima's burden as an immigrant, which is explained as 'a constant burden', is used to state her process of immigration. The dictionary meaning of a burden as a noun is a heavy load that you carry, and the responsibility, which is hard to bear. Literally, there is no physical burden. Nevertheless, the constant burden activates the scene of immigration being a burden to Ashima. as a result of the existence of contrast between the basic and the contextual meaning, the noun phrase' a constant burden' then is 
marked as a metaphorically used expression. Contextually, the noun phrase is used when Ashima describes her status as a foreigner; it foreshadows that the way she is burdened by the process of immigration. Experiencing immigration for Ashima is considered as an undesirable change that leads to a lifelong discomfort. Through Ashiam's thoughts, a pessimistic image of immigration is created, because the word 'burden' denotes the miseries of living abroad (Stoican, 2015, p 35). Conceptually, in the linguistic expression' a constant burden', the source domain of burden is mapped onto the target domain of immigration. through the mapping process the characteristics such as heaviness, stillness of the burden and feeling the heaviness and the weight of the hardships that she feel due to being an immigrant are mapped to the target domain of immigration. Therefore, both the process of immigration and the burden share the idea of experiencing hardships, and the target domain acquires a new structure, which is heaviness and weight. The mapping process between both domains helps the reader to understand the way that immigration is experienced by females in Lahiri's novel. The noun phrase' a constant burden' in the given context can be seen as the linguistic realization of the conceptual metaphor: IMMIGRATION IS BURDEN.

Similarly, in the same context, the status of being a foreigner causes Ashima to feel mentally displaced and sad. In the extract above, Lahiri constructs the source domain via the idiom 'out of sort'. Idioms play an important role in in structuring metaphorical expressions in our everyday concept, because "[t]he English expressions are of two sorts: simple literal expressions and idioms that fit the metaphor and are part of the normal everyday way of talking about the subject" (Lakoff \& Johnson, 2003, p. 47). The meaning of the idiom 'out of sort' is to feel unwell, displaced, and unhappy mood. These characteristics are mapped into the target domain of immigration from the source domain of 'out of sort'. Ashima experiences the feeling of out of sorts due to the process of immigration, and then it is understood from an abstract psychological state. For Mishra, the homeland which is India is responsible to keep the immigrants in the traumatic situation of displacement, and yearning for the lost homeland (Mishra, 2007, p. 58). As the result of mapping process, analogies and the similarities between both domains can be established. Thus, a new conceptual metaphor can be can be constructed which is IMMIGRATION IS DISPLACEMENT.

In another context and another main character, Ashoke, the representation of immigration occurs in his account. The context representing immigration occurs is when Ashoke is on the train to visit his grandparents in Jamshedpur, it was the first time that Ashoke wanted to spend the holiday away from his family, before he emigrates from India. Gosh, another passenger on the train, who has been to England and has recently returned permanently to India upon his wife's wish. He meets Ashoke on the train. He informs Ashoke that he has lived for two years in England on a job voucher, and had returned back to live in India only for the sake of his wife. Gosh describes, England as a dream, as "the sparkling empty streets, the polished black cars, and the row of gleaming white houses" (Lahiri, 2003, p.23). When Gosh shook his head. "You are still young. Free," (Lahiri, 2003, p.24). Gosh opens up to Ashoke and asks, to stay away from homeland and emigrate from India and he will not regret it (Ahmad, 2011, p. 97). Consequently, the indication of immigration is activated through Gosh's quest for Ashoke to emigrate from India. when Gosh talks to Ashoke he uses the body language to support the intended concept that he wants to deliver. Because when he was uttering the word free, he was "spreading his hands for emphasis" ((Lahiri, 2003, p.24). In the given utterance from the novel, the lexical, which is metaphorically used, should be identified, then to establish the mapping process between both domains. The contextual meaning of the adjective 'free' indicates that Ashoke needs to be free, while literally he is free and not imprisoned. Therefore, the contextual meaning contrasts its basic meaning, which is the dictionary meaning and it means when someone is literally imprisoned and needs to be free. Therefore, in this extract Ashoke's immigration is represented through the semantic item 'free'. Conceptually, since the adjective 'free' is used in a non-literal sense, it can be considered as the source domain that provides structures to describe the target domain of immigration. In addition, through the process of cross-domain mapping, the speaker maps selected features such as having access to be independent into the process of immigration. Mapping is activated through the domain of freedom into the domain of immigration, the act of freedom is explicitly is picked up by the speaker as referent to the process. Likewise, staying in the homeland, which is India in the given context, prevents one from being free, consequently, leaving homeland frees one from the ties and the obligations. The analogy between the two different domains is that immigration would give the chance of independency to Ashoke. The outcomes of this mapping are when you immigrate you are free, whereas staying in the homeland is the prison. As a result, we have a new constructed meaning that is not available explicitly in the given context. According to this context, the process of immigration is manifested in a positive way. Freedom means to be independent and having the right to choose. Thus, we can say that the linguistic realization of the context is the realization of conceptual metaphor: IMMIGRATION IS FREEDOM. In addition, this linguistic expression can be considered as the extension of the conceptual metaphor; IIMIGRATION IS A JOURNEY.

Another similar metaphorical expression occurs in the following extract, when the journey of immigration is conceptualized in terms of 'packing a pillow and a blanket' as Lahiri (2003) states: 
"You are still young. Free," he said, spreading his hands for emphasis. "Do yourself a favor. Before it is too late, without thinking too much about it first, pack a pillow and a blanket and see as much of the world as you can. You will not regret it. One day it will be too late. (p.24)

In this excerpt, the imperative sentence 'pack a pillow and a blanket' is also used in a metaphorical sense, because it portrays the way that immigrants look like when they emigrate from homeland. Lahiri creatively uses the notion of packing pillows and blankets, to indicate that immigration is a process that does not even need to over think but emigrate instantaneously. Many critics consider Lahiri's fiction as the representation of immigration and immigrant's portrait (Varma and Singh, 2019, p. 90). Moreover, John McLeod in Beginning Postcolonialism claims " [migrants] tend to arrive in new places with baggage; both in physical sense of possession or belonging, but less tangible matter of beliefs, traditions, customs, behaviors and values" ( McLeod, 2000, p. 211). In the given context no literal action of packing pillows and blankets are intended, but it is meant to give a non-literal implication, in which there is a contrast between the basic and the contextual meaning. Contextually, both speakers Gosh and Ashoke are the two passengers on the train to Jamshedpur. Gosh states that to leave this country, India, only needs packing a pillow and a blanket. Conceptually, in the above expression, the metaphorical focus 'packs a pillow and a blanket' which is metaphorically used depicts the notion of immigration in terms of a concrete act of packing. As for the conceptual mapping, the state of immigration is understood in terms of 'packing a pillow and a blanket', in which the target domain of the conceptual metaphor is immigration and the source domains are 'packing a pillow and a blanket'. To spell this out, the cross mapping between those two domains is presented through a physical activity when someone packs pillows and blankets. This metaphorical construction is visualized through an image activity, because usually when someone packs pillow and blanks, it connotes the process of moving from one place to another. Therefore, the above scenario is the activation of the target domain of immigration. As Lakoff and Johnson claim, "image-schema structure of the source domain is used in reasoning about the target domain" (Lakoff and Johnson, 2003, p.254). However, the act of immigration is implicitly understood in terms of packing a pillow and a blanket, due to the absence of the target domain. The mapping is structured from the act of packing pillows and blankets into the immigration process. The analogy is also based on the similarity between both images. The outcome of the cross- mapping is that the state of immigration is realized in a new physical and concrete way. Packing a pillow and a blanket considered as the linguistic realization of the constructed conceptual metaphor, immigration is packing a blanket and a pillow, through Lahiri's conceptualization of the immigration process. Another possible conceptual metaphor that can be concluded is, immigration is a journey, and hence it is an extension of the conceptual metaphor of LIFE IS A JOURNEY (Kövecses, 2002, p. 30).

\section{Conclusion}

In conclusion, the experience of immigration is a complex phenomenon, therefore to represent the process of immigration; Lahiri uses the metaphorical expressions to conceptualize the immigration in her novel The Namesake. The metaphorical expressions that represent immigration were approached in terms of the framework of cognitive, which is conceptual metaphor theory. The study shows that the conceptual metaphor theory is useful to analyze the way the metaphors of immigration are represented. In addition, the identification of source domain and target domain is useful to the process of cross-domain mapping. Because mapping between both domains is an effective way to establish the analogy between them, and structure the new constructed meaning. The process of immigration is represented through different scenarios that help the reader to understand the process of immigration clearly. This study presents a new tool to understand immigration. It shows the viability and the effectiveness of the methodology; however, it can be applied to the different discourses in different fields. Since new wave of immigration has started to the western countries, due to the war conflicts and the ISIS attacks to various places in the Middle East, then this cognitive-stylistic approach can be applied to the contexts in which this new wave of immigration is represented.

\section{References}

[1] Ahmed, S. (2011). Metaphors in Jhumpa Lahiri's Fiction: A Study [Doctoral dissertation]. Indian Institute of Technology Guwahati)

[2] Bala, S. (2002). Jhumpa Lahiri: The Master Storyteller A Critical Response to Interpreter of Maladies. Khosla Publishing House.

[3] Bran, R.A. (2014). Immigration:'a Lifelong Pregnancy': An Analysis of Jhumpa Lahiri's Fiction [Doctoral dissertation] Universitätsbibliothek Dortmund.

[4] Dennihy, M. (2012). [Review of the book Naming Jhumpa Lahiri: Canons and Controversies. Ed. Lavina Dhingra and Floyd Cheung] MELUS: Multi-Ethnic Literature of the United States, 37(3), 239-241.

[5] Dhingra, L. \& Cheung, F. (Eds.). (2011). Naming Jhumpa Lahiri: Canons and Controversies. Lexington Books.

[6] Hogan, P.C. (2003). Cognitive science, literature, and the arts: A guide for humanists. Psychology Press.

[7] Joshi, P. (2016). How many voices here?. A Study of the fictional works of Jhumpa Lahiri. International Journal of Multifaceted and Multilingual Studies, 3(7), 2-10.

[8] Kovecses, Z. (2002). Metaphor: A practical introduction. Oxford University Press.

[9] Kövecses, Z. (2010). Metaphor: A Practical Introduction. Oxford University Press.

[10] Kövecses, Z., (2012). Emotion concepts. Springer Science \& Business Media.

[11] Lahiri, J. (2004). The Namesake: A novel. Houghton Mifflin Harcourt. 
[12] Lakoff, G. \& Johnson, M. (2003). Metaphors We Live By. University of Chicago Press

[13] Lakoff, G. \& Turner, M. (1989). More than Cool Reason: A field Guide to Poetic Metaphor. University of Chicago press.

[14] Lakoff, G., \& Johnson, M. (1980). Metaphor we live by. University of Chicago Press.

[15] Macwan, H. (2014). A Study of Diasporic Sensibility and Acculturation in Jhumpa

[16] Mishra, V. (2007). The Literature of the Indian Diaspora: Theorizing the Diasporic Imaginary. Routledge.

[17] Mudge, A. (2003, September). Family Values: Lahiri Probes the Immigrant Identity in Her First Novel [interview], BookPage Archive. http://www.bookpage.com/0309bp/jhumpa lahiri.html

[18] Obama, B. (Sep 10 ${ }^{\text {th }}$ 2015). Remarks by the President at the National Medals of the Arts and Humanities Awards Ceremony. Office of the Press Secretary. Available Online at: https://obamawhitehouse.archives.gov/the-press-office/2015/09/11/remarks-president-nationalmedals-arts-and-humanities-awards-ceremony

[19] Pathak, V., Dabir, U. and Mishra, S. (Eds.). (2008). Contemporary Fiction: An Anthology of Female Writers. Sarup \& Sons.

[20] Raychaudhuri, A. (2018). Homemaking: Radical Nostalgia and the Construction of a South Asian Diaspora. Rowman \& Littlefield.

[21] Stoican, A.E., (2015). Transcultural Encounters in South-Asian American Women's Fiction: Anita Desai, Kiran Desai and Jhumpa Lahiri. Cambridge Scholars Publishing. 